\title{
The Science Case for ${ }^{37} \mathrm{Ar}$ as a Monitor for Underground Nuclear Explosions
}
DA Haas
HS Miley
JL Orrell
CE Aalseth
TW Bowyer JC Hayes
JI Mclntyre

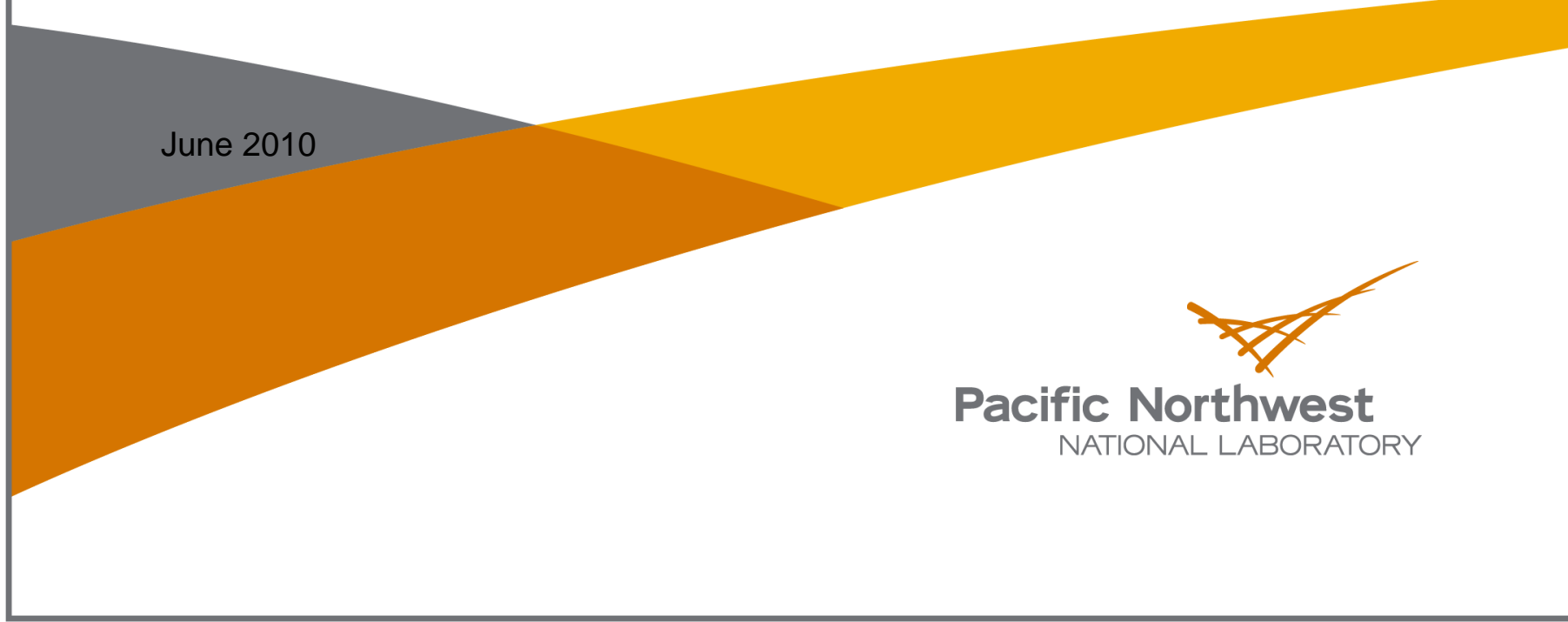




\title{
DISCLAIMER
}

This report was prepared as an account of work sponsored by an agency of the United States Government. Neither the United States Government nor any agency thereof, nor Battelle Memorial Institute, nor any of their employees, makes any warranty, express or implied, or assumes any legal liability or responsibility for the accuracy, completeness, or usefulness of any information, apparatus, product, or process disclosed, or represents that its use would not infringe privately owned rights. Reference herein to any specific commercial product, process, or service by trade name, trademark, manufacturer, or otherwise does not necessarily constitute or imply its endorsement, recommendation, or favoring by the United States Government or any agency thereof, or Battelle Memorial Institute. The views and opinions of authors expressed herein do not necessarily state or reflect those of the United States Government or any agency thereof.

\author{
PACIFIC NORTHWEST NATIONAL LABORATORY \\ operated by \\ BATTELLE \\ for the \\ UNITED STATES DEPARTMENT OF ENERGY \\ under Contract DE-AC05-76RL01830
}

Printed in the United States of America
Available to DOE and DOE contractors from the Office of Scientific and Technical Information,
P.O. Box 62, Oak Ridge, TN 37831-0062;
ph: (865) 576-8401
fax: $(865)$ 576-5728
email: reports@adonis.osti.gov

\begin{abstract}
Available to the public from the National Technical Information Service, U.S. Department of Commerce, 5285 Port Royal Rd., Springfield, VA 22161 ph: (800) 553-6847 fax: $(703) 605-6900$ email: orders@ntis.fedworld.gov online ordering: http://www.ntis.gov/ordering.htm
\end{abstract}

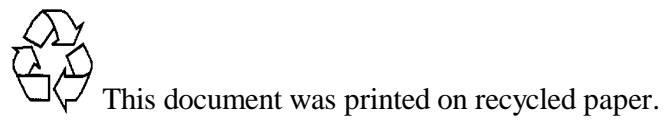




\title{
The Science Case for $37 \mathrm{Ar}$ as a Monitor for Underground Nuclear Explosions
}

\author{
DA Haas HS Miley \\ JL Orrell CE Aalseth \\ TW Bowyer JC Hayes \\ JI Mclntyre
}

June 2010

Prepared for the U. S. DEPARTMENT OF ENERGY under Contract DE-AC05-76RL01830

Pacific Northwest National Laboratory Richland, WA 99354 


\section{Summary}

This paper presents a new calculation of the production of ${ }^{37} \mathrm{Ar}$ from nuclear-explosion neutron interactions on ${ }^{40} \mathrm{Ca}$ in a suite of common sub-surface materials (rock, etc). Even in mineral structures that are relatively low in calcium, the resulting ${ }^{37} \mathrm{Ar}$ signature is large enough for detection in cases of venting or gaseous diffusion driven by barometric pumping. We present field and laboratory detection strategies and projected sensitivities herein. 


\section{Acknowledgements}

The authors thank R. Purtschert and S. Hebel for correspondence regarding their ${ }^{37}$ Ar measurements. 


\section{Contents}

$\begin{array}{lll}1.0 & \text { INTRODUCTION } & 1\end{array}$

2.0 METHOD 1

3.0 RESULTS 2

3.1 BACKGROUNDS - NATURALLY OCCURRING ${ }^{37}$ AR

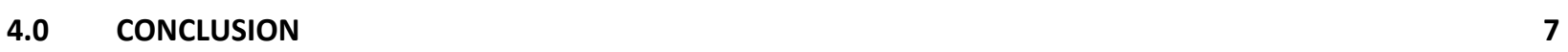

$\begin{array}{lll}\mathbf{5} .0 & \text { REFERENCES } & 8\end{array}$ 


\section{Figures}

Figure 1. Radioargon production by a $1 \mathrm{kT}$ nuclear explosion in various rock types....................... 3

Figure 2. Radioargon and radioxenon levels expected at the surface after a $1 \mathrm{kT}$ nuclear

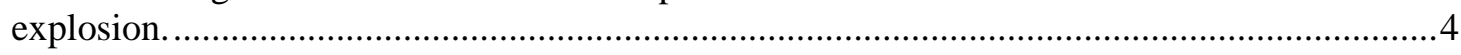

Figure 3. Radioargon and radioxenon levels expected at the surface after a $1 \mathrm{kT}$ nuclear explosion and probable background levels......................................................................

Figure 4. Measured sub-surface ${ }^{37} \mathrm{Ar}$ concentration levels at various locations $[5,12] \ldots \ldots \ldots \ldots \ldots \ldots . . .6$ 


\subsection{Introduction}

Underground nuclear explosions represent a significant source term for seismic and hydroacoustic measurements, and can be readily detected by sensors of the Comprehensive Nuclear-Test-Ban Treaty Organization's (CTBTO) International Monitoring System (IMS). Such an explosion may or may not vent radioactive atoms. Some experiments have demonstrated that about half the underground explosions at one site leaked significant radioactive xenon isotopes [Dubasov 2010]. Even in the case of a modest leak, uncertainties in atmospheric backtracking or the lack of any radioactive atoms detected by IMS sensors from an event of interest may make an On-Site Inspection (OSI) a key to verifying compliance with the CTBT.

Two interesting noble gases are produced in underground explosions: xenon isotopes from fission $\left({ }^{131 \mathrm{~m}} \mathrm{Xe},{ }^{133} \mathrm{Xe},{ }^{133 \mathrm{~m}} \mathrm{Xe}\right.$, and $\left.{ }^{135} \mathrm{Xe}\right)$ and ${ }^{37} \mathrm{Ar}$ from the ${ }^{40} \mathrm{Ca}(\mathrm{n}, \alpha){ }^{37} \mathrm{Ar}$ reaction. The production of xenon from fission products is well known, as is the reaction of neutrons with calcium [England 1995; Chadwick 2006]. The transport of gas from an explosion cavity to the surface under the influence of barometric pumping has been modeled and measured in one experiment [Carrigan 1997]; however, the production rate of ${ }^{37} \mathrm{Ar}$ per neutron underground in an extended medium of rock or other material has not been published. Key issues are the quantity of calcium in the target material and the neutron energy spectrum.

Experiments determining the ${ }^{37}$ Ar background in soil gas are sparse. The work of Purtschert [2007] shows the concentration varies with the depth and calcium content of the soil or rock. Radioxenon backgrounds modeled in Hebel [2010] show ${ }^{133} \mathrm{Xe}$ and ${ }^{135} \mathrm{Xe}$ underground can be present at levels higher than the detection limits of current radioxenon detection systems [Ringbom 2003].

\subsection{Method}

The ${ }^{37} \mathrm{Ar}$ source term was modeled through a highly conservative deterministic method as well as a Monte Carlo method using MCNPX. In the rough deterministic model, we solved for the macroscopic neutron interaction cross section in eight rock types [Fabryka-Martin 1988; Parker 1967]. The cross section for the ${ }^{40} \mathrm{Ca}(\mathrm{n}, \alpha)^{37} \mathrm{Ar}$ reaction is highest at energies greater than $1 \mathrm{MeV}$ and the neutrons produced in an underground nuclear explosion would follow a Watt fission neutron spectrum. Therefore, the ${ }^{37} \mathrm{Ar}$ produced by the uncollided neutron flux provides a rough measure of the overall quantity produced. Equation 1 gives the ${ }^{37} \mathrm{Ar}$ production rate in atoms as a function of number of fissions and rock type.

$N_{A r}=\int_{V}\left(\frac{\phi_{0}}{r^{2}}\right) e^{\left(-r \Sigma_{T}\right)} \sigma\left[{ }^{40} \mathrm{Ca}\left(n_{i} \alpha\right)\right] \rho\left[{ }^{40} \mathrm{Ca}\right] d V$

This equation makes the following conservative assumptions:

- Any neutron that interacts with the rock does not retain enough energy to initiate the $(n, \alpha)$ reaction to produce ${ }^{37} \mathrm{Ar}$

- No thermal production

- Interactions that could create neutrons $(n, f),(n, 2 n)$ are ignored 
The above assumptions are conservative in the present context because they each will result in a slight underestimation of the total activity produced. The number of atoms produced was converted to activity and multiplied by the factor that Carrigan [1997] reported for the dilution of ${ }^{37} \mathrm{Ar}$ as it migrates to the surface. This factor is geology dependent and therefore provides a significant uncertainty in the activity seen at the surface and the time at which the gas reaches the surface. However, the use of a dilution factor is a necessary step to convert the argon production results to numbers that are relevant to detection systems.

After completing the deterministic model, we ran an MCNPX model to determine the neutron flux profile as a function of radius in each rock type. The geometry of the model consisted of a point source of Watt fission spectrum neutrons in each rock type with flux tallies at increasing radii. To calculate the number of ${ }^{37} \mathrm{Ar}$ atoms produced, the output-energy-dependent neutron flux at each radius was multiplied by the energy-dependent cross sections for the $(\mathrm{n}, \alpha)$ reaction in ${ }^{40} \mathrm{Ca}$ using Equation 2. The results from this model were also converted to activity and multiplied by the dilution factor.

$N_{A r}=\sum_{i, j}\left[\phi_{E_{i,} r_{j}} \sigma_{E_{\mathrm{i}}}\left[{ }^{40} C a(n, \alpha)\right]^{n\left[{ }^{40} C a\right.}\right]^{\left.4 \pi\left(r_{j}^{3}-r_{j-1}{ }^{3}\right)\right]}$

\subsection{Results}

The results of the deterministic and Monte Carlo models agree to within an order of magnitude. This is not unexpected due to the conservative nature of the deterministic model. The activity of ${ }^{37} \mathrm{Ar}$ expected at the surface 80 days after a $1 \mathrm{kT}$ nuclear explosion in various rock types is shown in Figure 1. As seen in the figure, the lowest activity is associated with halite and the highest activity with carbonate.

Figure 2 combines these results with data on radioxenon levels produced in a $1 \mathrm{kT}$ nuclear explosion. Figure 3 incorporates background measurements of ${ }^{37} \mathrm{Ar}$ and models of radioxenon background levels. The detection limits of several noble gas detection systems are shown to give an idea of the timeframe the gases are detectable post-detonation. The detection limits of the SAUNA system for radioxenon measurements are on the order of $2 \mathrm{mBq} / \mathrm{SCM}$ and $0.2 \mathrm{mBq} / \mathrm{SCM}$ in field and laboratory environments, respectively. The detection limit of the MARDS [Xiang 2008] in-field ${ }^{37} \mathrm{Ar}$ detection system is reported as $500 \mathrm{mBq} / \mathrm{SCM}$ [Tanaka 2008]. PNNL researchers have calculated the lower limit on an ${ }^{37} \mathrm{Ar}$ field system to be $\sim 20 \mathrm{mBq} / \mathrm{SCM}$ and the lower limit on a lab system for ${ }^{37} \mathrm{Ar}$ detection to be $\sim 0.02 \mathrm{mBq} / \mathrm{SCM}$. 


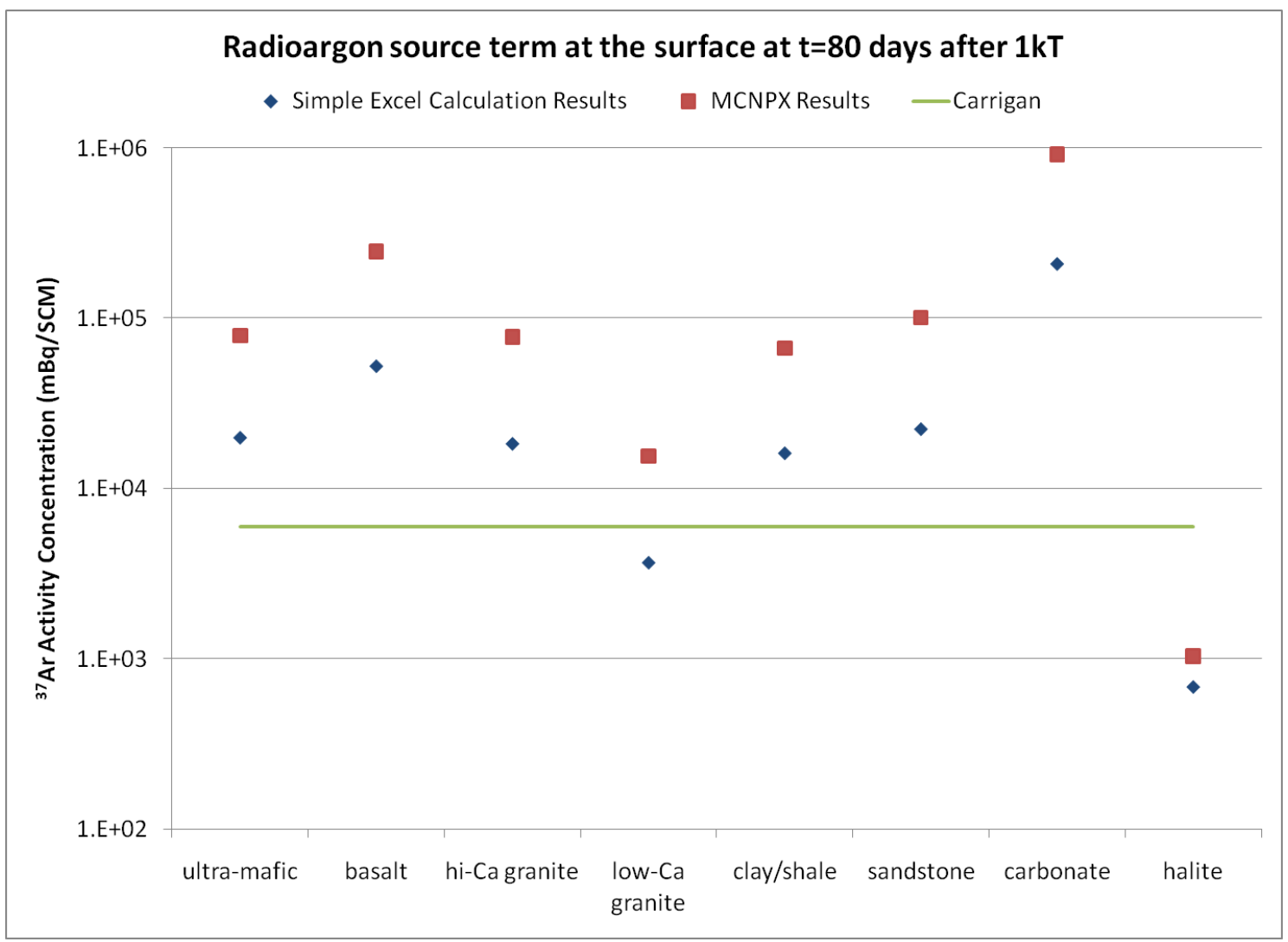

Figure 1. Radioargon production by a $1 \mathrm{kT}$ nuclear explosion in various rock types 


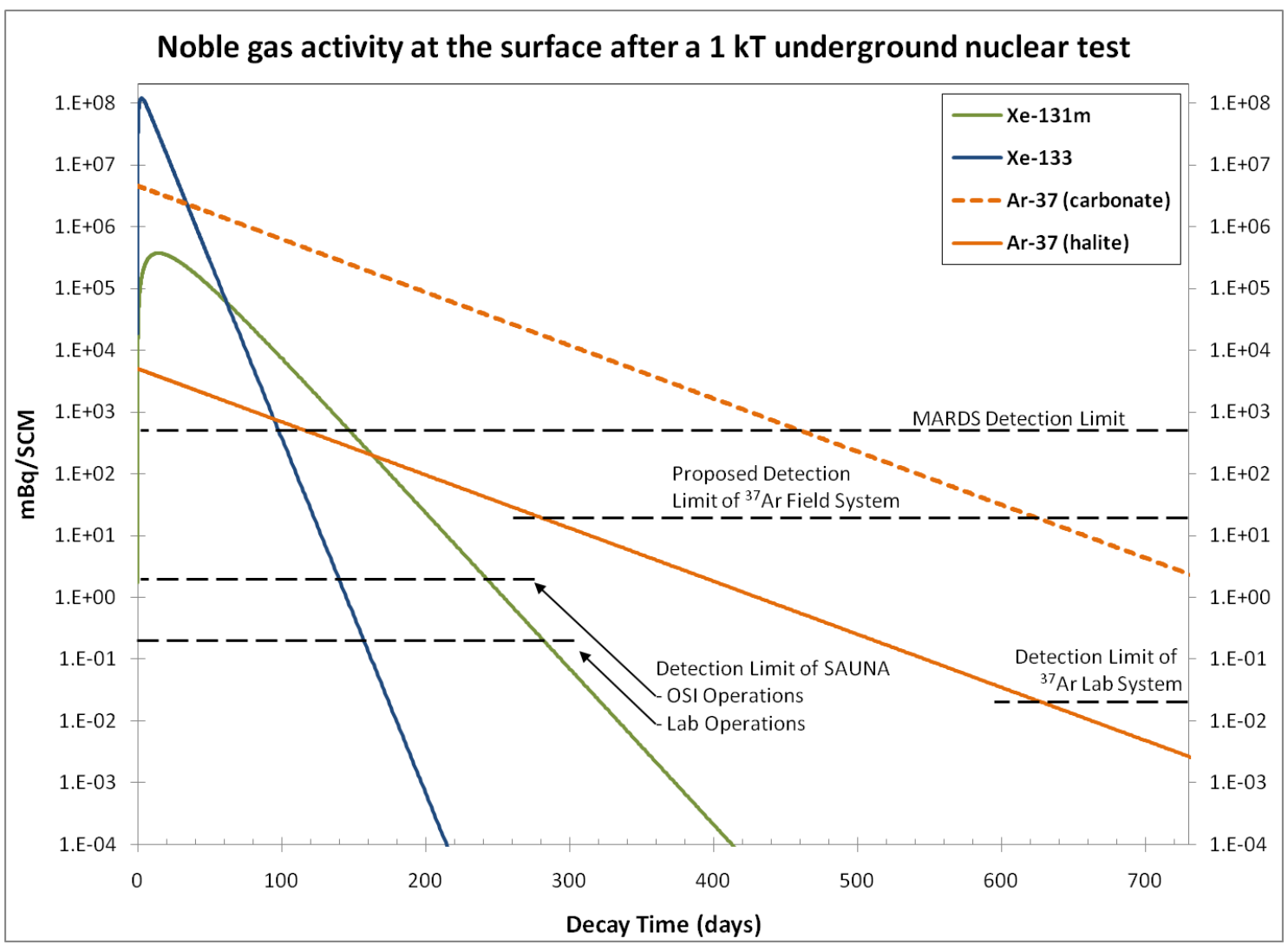

Figure 2. Radioargon and radioxenon levels expected at the surface after a 1 kT nuclear explosion 


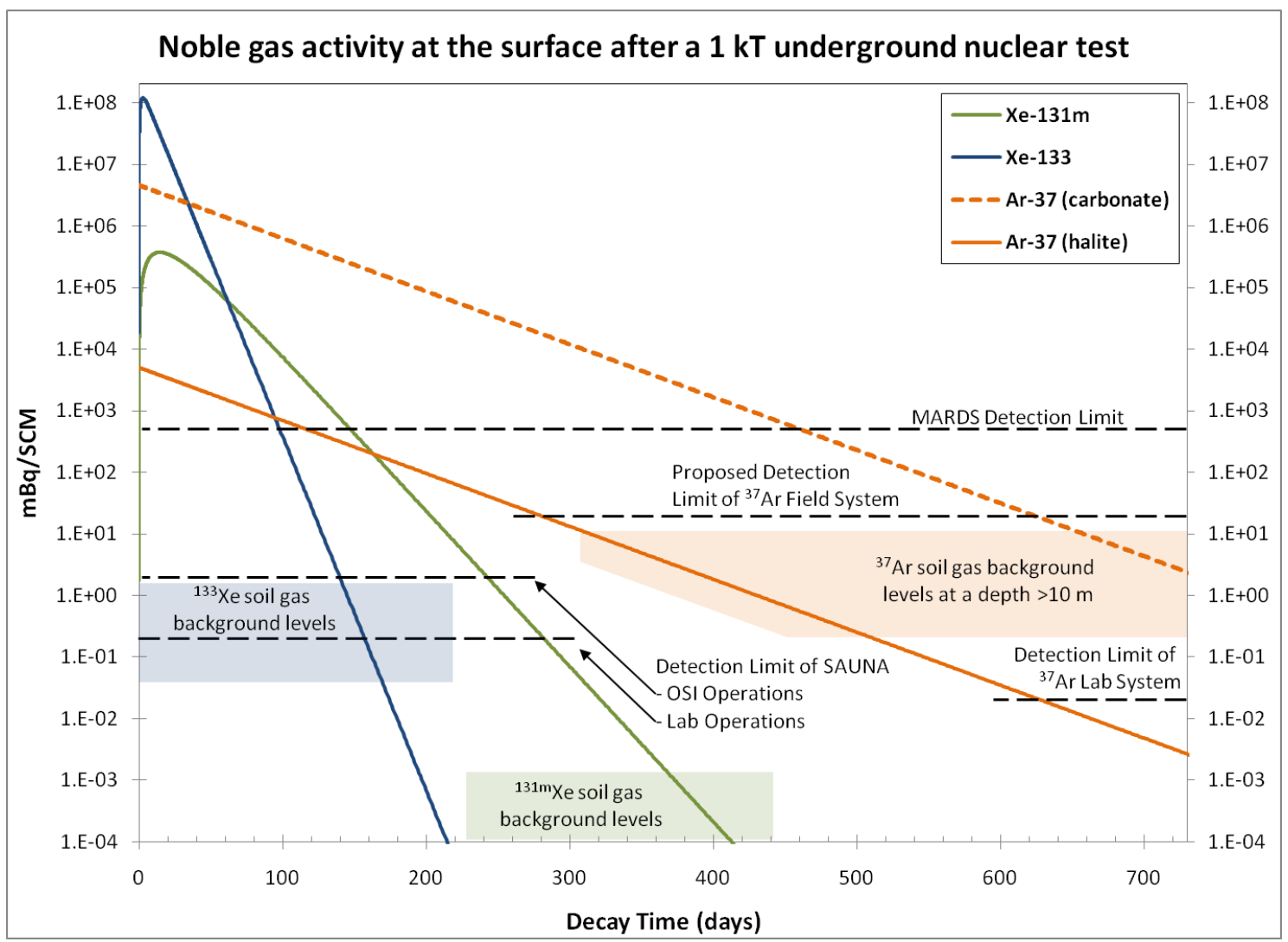

Figure 3. Radioargon and radioxenon levels expected at the surface after a $1 \mathrm{kT}$ nuclear explosion and probable background levels

\subsection{Backgrounds - Naturally Occurring ${ }^{37} \mathrm{Ar}$}

Figure 3 presents a band of the concentration levels expected for ${ }^{37} \mathrm{Ar}$ soil gas background levels as produced through natural processes [Purtschert 2007; Tanaka 2010]. The expectation band ranges from $0.2 \mathrm{mBq} / \mathrm{SCM}$ to $10 \mathrm{mBq} / \mathrm{SCM}$ for gas drawn from a soil depth greater than 10 meters. A similar band of concentration levels for gas drawn from soil depths less than 10 meters would generally range from $10 \mathrm{mBq} / \mathrm{SCM}$ to $100 \mathrm{mBq} / \mathrm{SCM}$. Figure 4 shows the experimental basis for setting these expectation bands in Figure 3. 


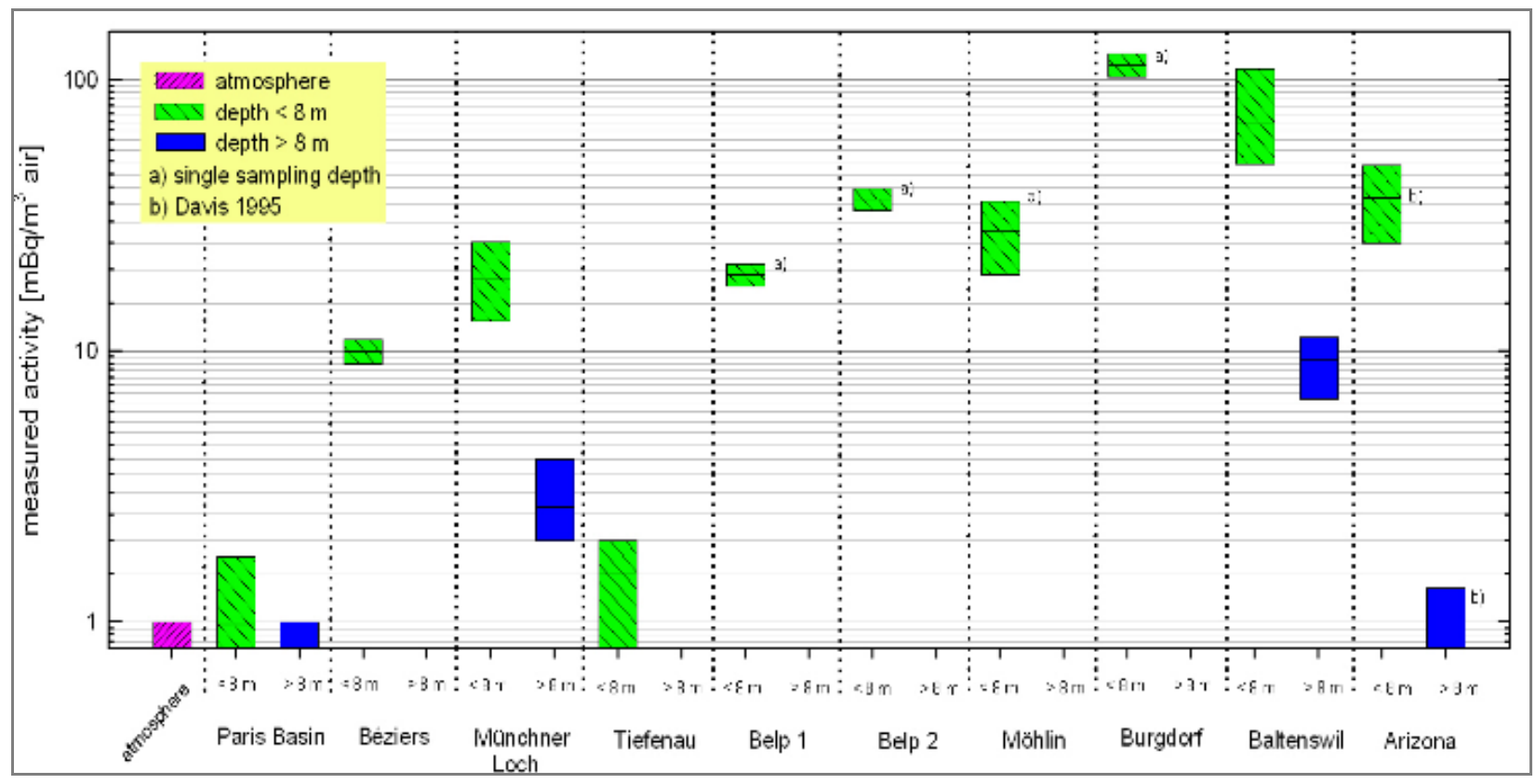

Figure 4. Measured sub-surface ${ }^{37} \mathrm{Ar}$ concentration levels at various locations [Purtschert 2007; Tanaka 2008]

The variability of the naturally occurring background levels of ${ }^{37} \mathrm{Ar}$ is predominately driven by factors relating to the local soil's exposure to cosmic-ray induced neutrons. Assuming gas samples for ${ }^{37} \mathrm{Ar}$ measurement are drawn either from near-surface or sub-surface points, the naturally occurring concentration levels of ${ }^{37} \mathrm{Ar}$ are expected to depend on the following factors:

- Calcium content of the soil

- Depth of the gas sample draw

- Geomagnetic latitude of the sampling location

- Altitude of the sampling location

- Mobility of the gas through the soil matrix

The calcium content of the soil directly impacts the number of target calcium nuclei in the soil with which cosmic ray induced neutrons can interact and produce ${ }^{37} \mathrm{Ar}$. The depth of the gas sample draw is related to the attenuation of cosmic-ray-induced neutrons in the intervening soil. At greater depth, there are fewer remaining neutrons that may initiate the production of ${ }^{37} \mathrm{Ar}$. The geomagnetic latitude of the sampling location is important because at higher latitude the intensity of the cosmic rays is greater, increasing the flux of cosmic-ray-induced neutrons reaching the surface, and thus ultimately resulting in a greater ${ }^{37} \mathrm{Ar}$ production rate. Likewise, altitude of the sampling is important, as higher elevations will have a greater flux of cosmic-ray-induced neutrons. The final item, mobility of gas through the soil matrix is not related to cosmic rays, but does directly impact the ability to extract and collect the ${ }^{37} \mathrm{Ar}$ gas from the soil. Gas mobility through the soil would also be expected to impact the ability to collect "signal" gases (radioxenon or ${ }^{37} \mathrm{Ar}$ ) produced from an underground nuclear detonation. 


\subsection{Conclusion}

The results presented here demonstrate that detectable levels of ${ }^{37} \mathrm{Ar}$ will be produced by underground nuclear explosions even in the very low calcium geologic structures studied here. The focus of an ${ }^{37} \mathrm{Ar}$ field system should be on improving the detection limit to extend the window of opportunity for detection, which can be achieved through development of detector, sample collection, and sample processing systems. This work also suggests that CTBTO should include ${ }^{131 \mathrm{~m}} \mathrm{Xe}$ as a signature of interest for OSI in the event of a slow seep of radioactive noble gases. While this work provides a better understanding of ${ }^{37} \mathrm{Ar}$ levels likely to be produced in an underground nuclear explosion, more detailed analysis is justified. Additional future work should include further testing of migration of radioactive noble gases underground and a better understanding of background levels of radioxenon and ${ }^{37} \mathrm{Ar}$ in soil gas. 


\subsection{References}

Carrigan, CR, et al. 1997. Barometric Gas Transport Along Faults and Its Application to Nuclear TestBan Monitoring.

Chadwick, MB, et al. 2006. "Next Generation Evaluated Nuclear Data Library for Nuclear Science and Technology." Nuclear Data Sheets 107(12):2931-3060.

Dubasov, YV. 2010. "Underground Nuclear Explosions and Release of Radioactive Noble Gases." Pure and Applied Geophysics 167(4-5):455-61. DOI: 10.1007/s00024-009-0026-Z.

England, TR, and BF Rider. 1995. Evaluation and Compilation of Fission Product Yields. Report No. LA-UR-94-3106, Los Alamos National Laboratory, Los Alamos, NM.

Fabryka-Martin, JT. 1988. "Production of Radionuclides in the Earth and Their Hydrogeologic Significance, with Emphasis on Chlorine-36 and Iodine-129." University of Arizona, Tuscon: Department of Hydrology and Water Resources. Dissertation for PhD. 423 pp.

Hebel, S. 2010. "Genesis and Equilibrium of Natural Lithospheric Radioxenon and Its Influence on Subsurface Noble Gas Samples for CTBT On-site Inspections." Pure and Applied Geophysics 167(45):463-70. DOI: 10.1007/s00024-009-0037-9.

Parker, RL. 1967. "Composition of the Earth's Crust, Data of Geochemistry." In Data of Geochemistry: U.S. Geological Survey Professional Paper 440-D, ed. M Fleischer, pp. 19. United States Geological Survey, Reston, VA.

Purtschert, R, R Riedmann, and H Loosli. 2007. "Evaluation of Argon-37 as a Means for Identifying Clandestine Subsurface Nuclear Tests." in 4th Mini Conference on Noble Gases in the Hydrosphere and in Natural Gas Reservoirs, eds. J Lippmand-Pipke and W Aeschbach-Hertig, Accessed at Deutsche Forschungsgemeinschaft, Bonn, Germany, Potsdam, Germany.

Ringbom, A, et al. 2003. "Sauna - a System for Automatic Sampling, Processing, and Analysis of Radioactive Xenon." Nuclear Instruments and Methods in Physics Research, Section A: Accelerators, Spectrometers, Detectors and Associated Equipment 508(Compendex):542-53.

Tanaka, J. 2008. "Argon-37 Measurements for on-Site Inspection." Accessed at, Presented at the International Noble Gas Experiment Workshop, St. Petersburg, Russia.

Tanaka, J. 2010. E-mail from Junichi Tanaka (CTBTO) to Harry Miley (Pacific Northwest National Laboratory) with PDF attachment, "Evaluation of Argon-37 as a Means for Identifying Clandestine Subsurface Nuclear Tests." March 28, 2010, Richland, WA. PDF document on file at CTBTO.

Xiang, Y-C, et al. 2008. "Development of a System of Measuring Ar-37 by Spectrum Method." Acta Physica Sinica 57(2):784-89. 


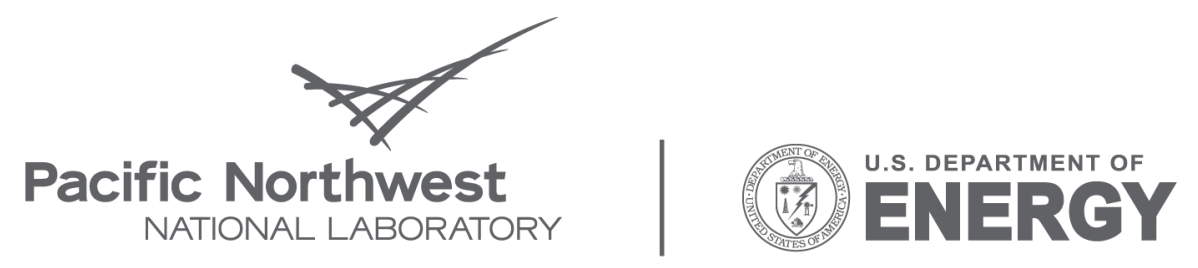

Proudly Operated by Battelle Since 1965

902 Battelle Boulevard

P.O. Box 999

Richland, WA 99352

1-888-375-PNNL (7665)

www.pnl.gov 